\title{
Verbal Abuse among Nurses in Tertiary Care Hospitals
}

\author{
Kalpana Silwal, ${ }^{1}$ Sarala Joshi ${ }^{2}$ \\ ${ }^{1}$ Chitwan Medical College, Bharatpur, Chitwan, Nepal, ${ }^{2} \mathrm{Om}$ Health Institute, Nursing College, Kathmandu, Nepal.
}

\section{ABSTRACT}

Introduction: Verbal abuse against nurses who are major working force can affect the work performance and productivity in hospital. Verbal abuse is epidemic in tertiary care hospitals though it is most preventable with healthcare professions. The study aims to identify the prevalence of verbal abuse among nurses in a Tertiary Care Hospital.

Methods: A descriptive cross-sectional study was conducted among nurses in two tertiary care hospitals in Chitwan using self-administered questionnaire from August-December, 2018. The researcher used the convenient sampling technique and total 331 nurses were taken for the study.

Results: Prevalence of verbal abuse was found to be 122 (36.9 \%) [34.25\%-39.55\% at 95\% CI] among nurses. Perpetrators of the verbal abuse were relatives of the patients $64(48.9 \%)$ followed by staff member $29(23.77 \%)$, patient $23(17.6 \%)$, management or supervisor $4(3.1 \%)$ and from colleague 2 (1.5\%). Frequency of verbal abuse as sometimes, once and all the times were 95 (77.86\%), 20 (16.03\%) and $7(5.7 \%)$ respectively. Study showed that verbal abuse was mostly done by relatives of the patient. Consequence of verbal abuse was disturbing memories, thoughts or an image ultimately reducing the job satisfaction. No any action was taken except verbal warning for 20 (58.8\%) perpetrators.

Conclusions: Verbal abuse is frequently prevalent in nurses and mostly from patient's visitors. Hence, nurses should maintain their respect and authority otherwise it will lead to decrease in their performance that shows direct impact on patient care and consequently the effectiveness of the health care system.

Keywords: nurses; verbal abuse; workplace.

\section{INTRODUCTION}

Verbal abuse in nursing is quite costly to the individual nurses, the hospitals and the patients. Nurses who regularly experience verbal abuse may be more stressed, may feel less satisfied with their jobs, miss more work and provide a substandard quality of care to patients. Workplace violence is a serious and common widespread phenomenon. ${ }^{1}$ Nurses face more violence than other professions. Nurses as frontier care providers serve in a wide variety of settings caring for individuals are suffering life-altering events. ${ }^{2}$

Nurses are invaluable members of the organization's work place team. ${ }^{3}$ Specially verbal abuse has a significant impact on the efficiency and effectiveness of healthcare providers. ${ }^{4}$ Nurses are at such a high risk of exposure to violent behaviours. ${ }^{5}$ Consequences of workplace violence affects quality of life. ${ }^{6}$

Therefore, the researcher intends to identify the prevalence of verbal abuse among nurses in tertiary care hospitals.

Correspondence: Kalpana Silwal, Chitwan Medical College, Bharatpur, Chitwan, Nepal. Email: kalpanasilwal@gmail.com, Phone: $+977-9841516491$. 


\section{METHODS}

A descriptive cross-sectional study was done in two tertiary care hospitals, Chitwan Medical College Teaching Hospital and Bharatpur Government Hospital within Chitwan from August to December, 2018. Ethical approval was taken from Nepal Health Research Council (NHRC).

Sample size was calculated as below:

$$
\begin{aligned}
\mathrm{n} & =\mathrm{Z}^{2} \mathrm{pq} / \mathrm{e}^{2} \\
& =(1.96)^{2} \times 0.299 \times 0.701 /(0.05)^{2} \\
& =316
\end{aligned}
$$

where,

$\mathrm{n}=$ sample size

$p=$ prevalence of the similar previous study ${ }^{2}$

$q=1-p$

$\mathrm{e}=$ margin of error, $5 \%$

So, the final sample size is 316 .

Using convenient sampling technique, the sample size of 185 and 146 were taken respectively from Chitwan Medical College and Bharatpur Government Hospital respectively. They were included if more than six months experienced in their recent workplace. Researcher's target was all the nurses of these hospitals with minimal of six months of experience. The participation in the study was voluntary. A self-administered structured anonymous questionnaire was used to get information from the participants. Verbal consent was taken before distributing questionnaire.

During the research, 356 respondents were included. Out of 356, only 337 questionnaires were returned among which six of the data sheet were not filled properly so that was discarded, thus 331 questionnaires were valid for analysis. Data was analyzed by SPSS 20 version and descriptive analysis was done to identify prevalence of workplace violence. Statistical analysis was performed to calculate the outcome in frequency and percentage.

\section{RESULTS}

Prevalence of verbal abuse was 112 (36.9\%) Cl $(34.25 \%-39.55 \%)$ among nurses in tertiary care hospitals. Most 95 (77.86\%) nurses are abused sometime and nurses who were all the times abused were 7 (5.7\%). Most common perpetrators 64 (48.9\%)

\begin{tabular}{|c|c|}
\hline Statements & n (\%) \\
\hline $\begin{array}{l}\text { Have you ever been verbally abused } \\
\text { (Total answered sample }=331 \text { ) }\end{array}$ & $122(36.9)$ \\
\hline $\begin{array}{l}\text { How often (Total answered } \\
\text { sample }=122)\end{array}$ & \\
\hline All the times & $7(5.7)$ \\
\hline Sometimes & $95(77.86)$ \\
\hline Once & $20(16.03)$ \\
\hline \multicolumn{2}{|l|}{ Perpetrators ( by Whom), $n=122$} \\
\hline Patient/client & $23(17.6)$ \\
\hline Relatives of the patient/client & $64(48.9)$ \\
\hline Staff member & $29(23.77)$ \\
\hline Management /supervisor & $4(3.1)$ \\
\hline Colleague & $2(1.5)$ \\
\hline
\end{tabular}
were relatives of the patient and least common 2 $(1.5 \%)$ perpetrators were colleague (Table 1$)$.
Pattern of responses towards verbal abuse is by reporting to seniors which is by $35(27.3 \%)$ and least $5(4.09 \%)$ are sought for counselling. Other responses, on avoiding thinking about or talking about the abuse or avoiding having feelings related to it highest falls

\begin{tabular}{|c|c|}
\hline \multirow{2}{*}{\multicolumn{2}{|c|}{$\begin{array}{l}\text { Table 2. Consequences Pattern after being verbal } \\
\text { abused. } \\
\text { Repeated, disturbing memories, thoughts or images } \\
\text { of the abuse (Total answered }=122 \text { ) }\end{array}$}} \\
\hline & \\
\hline Statement & n (\%) \\
\hline Took no action & $22(17.2)$ \\
\hline Tried to pretend it never happened & $19(14.8)$ \\
\hline Told the person to stop & $21(16.4)$ \\
\hline Told friends/family & $9(7)$ \\
\hline Told colleague & $11(8.6)$ \\
\hline Report it to senior staff members & $35(27.3)$ \\
\hline Sought counseling & $5(4.09)$ \\
\hline \multicolumn{2}{|c|}{$\begin{array}{l}\text { Avoiding thinking about or talking about the abuse or } \\
\text { avoiding having feelings related to it }\end{array}$} \\
\hline Statement & n (\%) \\
\hline $\begin{array}{l}\text { Avoiding thinking about or talking } \\
\text { about the abuse or avoiding having } \\
\text { feelings related to it, not at all }\end{array}$ & $\begin{array}{l}17 \\
(13.93)\end{array}$ \\
\hline $\begin{array}{l}\text { Avoiding thinking about or talking } \\
\text { about the abuse or avoiding having } \\
\text { feelings related to it, A little bit }\end{array}$ & $30(24.5)$ \\
\hline $\begin{array}{l}\text { Avoiding thinking about or talking } \\
\text { about the abuse or avoiding having } \\
\text { feelings related to it, moderately }\end{array}$ & 56 (45.9) \\
\hline $\begin{array}{l}\text { Avoiding thinking about or talking } \\
\text { about the abuse or avoiding having } \\
\text { feelings related to it, quiet a bit }\end{array}$ & $\begin{array}{l}19 \\
(15.57)\end{array}$ \\
\hline
\end{tabular}
on moderately is $56(45.9 \%)$ and least is $17(13.93 \%)$ (Table 2). 
Patterns of supporting system to report or to investigate is highest , $24(70.6 \%)$ from management or employer and least from community group is 2 $(5.9 \%)$. Consequences for perpetrators is only verbal warning is for $20(58.8 \%)$ and aggressor prosecuted is only 2 (5.8\%). Respondent's satisfaction on handling manner of the incident is only sometimes satisfaction is $11(32.3) \%$ is higher than others followed by never satisfied $7(20.5 \%)$ as shown (Table 3$)$.

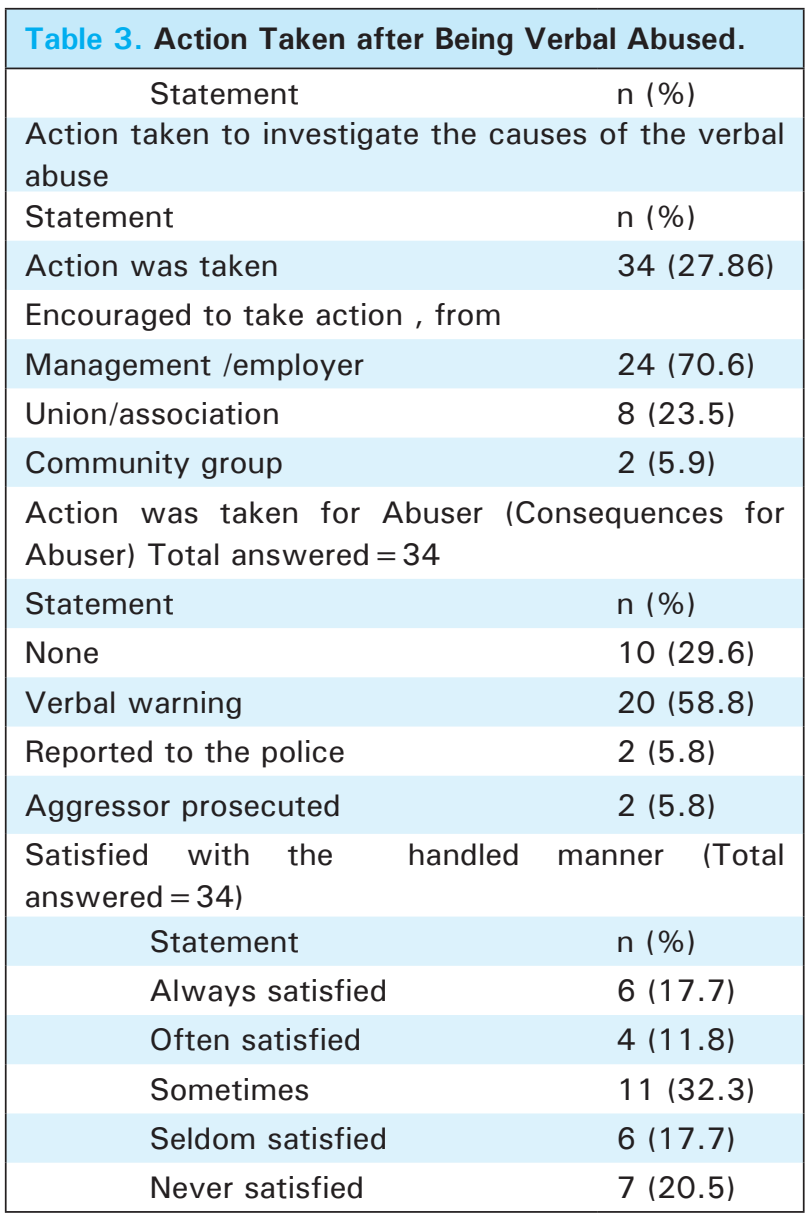

Respondents' response not to report for the incident is more in afraid of negative consequences is 15 (44.1\%) and least in felt ashamed is $2(5.9 \%)$ as shown (Table 4).

\begin{tabular}{|ll|}
\hline $\begin{array}{l}\text { Table 4. Reasons not to Report for } \\
\text { Violence. }\end{array}$ & Workplace \\
\hline $\begin{array}{l}\text { Statement } \\
\text { sample }=34)\end{array}$ & answered \\
It was not important & $7(20.6 \%)$ \\
Felt ashamed & $2(5.9 \%)$ \\
Felt guilty & $6(17.6 \%)$ \\
Afraid of negative consequences & $15(44.1 \%)$ \\
Did not know who to report to useless & $4(11.8 \%)$ \\
\hline
\end{tabular}

Most $245(74.6 \%)$ of the respondents were the age of $21-25$ years and least $7(2.1 \%)$ were the age of 31-35 years. Mean age of the respondents was $24.5 \pm 5.079$ years.

Majority 201 (60.7\%) of the respondents were married and $244(73.8 \%)$ were full time workers.

\section{DISCUSSION}

The study shows prevalence of the verbal abuse is $36.9 \%$ among the nurses. Studies conducted in one of the tertiary care institution of Nepal and in Baglung district of Nepal found that $40 \%$ and $47.7 \%$ of health workers were verbally abused. ${ }^{4,5}$ A study showed that verbal abuse was experienced by $87.4 \%$ of the population during a 6-month period. ${ }^{7}$ Other study showed that 50 percent registered nurses and nursing students reported being verbally abuse in a 12 month period. ${ }^{8}$ Other studies have reported two-thirds of verbal workplace violence. ${ }^{9}$ The proportion of verbal violence was higher $(61.5 \%) .{ }^{10}$ Different study showed different results so by World Health Organization recommended to record incidents of verbal abuse and threats and evaluate the record on a monthly basis by department safety committee. Reporting systems should be user friendly: easy to understand, not too time consuming and accessible. ${ }^{4}$

This study revealed that $48.9 \%$ perpetrators were relatives of the patient or client. A study conducted in Baglung district also showed that the perpetrators of all three types of violence (physical, verbal abuse and sexual harassment) were mostly the relatives of patients. Incidents took place mostly inside the health institution for verbal abuse (84.5\%). ${ }^{4}$

Pattern of responses towards verbal abuse by the victims showed that $27.3 \%$ told their seniors about the event and only $16.4 \%$ of the respondents had told to person to stop for verbal abuse. A study reported that most of the victims of physical violence reported that they told the perpetrators to stop (72.7\%) and only $4 \%$ had told to their seniors of their verbal abuse. Same study also reported that $3 \%$ sought for counselling. ${ }^{4}$ Recent study shows $4.09 \%$ sought for counselling, which is similar to findings.

In this study, $44.1 \%$ of respondents didn't report for the incident due to fear of negative consequences is which is similar to this study. ${ }^{5}$ In this study, the extent of the repeated, disturbing memories, thoughts or images after the experience of verbal abuse was surprisingly rated as little bit by $36.8 \%$ of the respondents. A study showed that psychological consequences resulting from violence may include fear and frustration. ${ }^{7}$ Similar study showed that nurses experienced at least one 
post-traumatic stress disorder symptom after a violent event by $94 \% .^{6}$

Study reports that most $(34.4 \%)$ of the respondents are moderately "super alert" after being verbal abuse and extremely "super alert" is $4.09 \%$. One of the study showed that health workers always feel stress and hazardous in their workplace after being verbal abuse. ${ }^{9}$ One of the study reported that the effects of abuse on nurses produce sleeping disorders, stress, self dissatisfaction and disappointment. ${ }^{10}$ Nurses suffered from psychological, physical and occupational stress was often due to the workplace violence. ${ }^{8}$ Stress and violence are increasingly noted in health sector workplaces. Doctors, nurses and social workers are all high on the list of occupations with serious stress levels, while violence in the health sector constitutes almost a quarter of all violence at work. The enormous cost of work stress and violence at work for the individual, the workplace and the community at large is becoming more and more apparent. ${ }^{11}$ Negative stress as a source of violence has been identified for several occupations. Negative stress activates a variety of physical and emotional symptoms that can lead to serious illness. ${ }^{12}$

This study shows consequences for perpetrators is only verbal warning accounting $58.8 \%$ and $5.8 \%$ of the aggressors prosecuted. Likewise patterns of supporting system to report or to investigate is highest $70.6 \%$ from management or employer and least $5.9 \%$ from community group. In the US $100 \%$ of respondents witnessed verbal violence, whereas only $23 \%$ of verbal abuse cases were reported. ${ }^{9}$ In India, a study showed that verbal abuse witnessed was $89 \%$ but the reported cases was only from $46 \% .^{7}$ Today, there is increased evidence that health staff especially nursing staffs are at such a high risk of exposure to violent behaviours in the workplace; it is now considered to be a major occupational hazard worldwide. ${ }^{11}$

The study was limited to only two tertiary level hospitals. It was limited only on structured questionnaire and verbal abuse might be among other healthcare stakeholders but this study is only limited within Nurses only.

\section{CONCLUSIONS}

Verbal abuse is frequently prevalent in nurses and mostly from patient's or client's visitors. Hence, nurses should maintain respected and authorized place if not it will lead to decrease in performance which will have direct impact on patient care and consequently the effectiveness of the health care system.

\section{ACKNOWLEDGEMENTS}

I acknowledge to the help of Lecturer Ms Taniya Thapa and Lecturer Ms Alisha Joshi, Chitwan Medical College, School of Nursing . I also express gratitude to my friend Associate Professor Tumla Shrestha (PhD Schloar) Maharajgunj Nursing Campus ,all the respondents who participated in the study and all the people who helped me during my data collection period.

\section{Conflict of Interest: None.}

\section{REFERENCES}

1. Kwok RP, Law YK, Li KE, Ng YC, Cheung MH, Fung VK, Kwok KT, Tong JM, Yen PF, Leung WC. Prevalence of workplace violence against nurses in Hong Kong. Hong Kong Med J. 2006 Feb;12(1):6-9. [PubMed]

2. Fute M, Mengesha ZB, Wakgari N, Tessema GA. High prevalence of workplace violence among nurses working at public health facilities in Southern Ethiopia. BMC Nurs. 2015 Mar 3;14:9. [PubMed | Full Text | DOI]

3. Robinson I. Prevention of Workplace Violence Among Health Care Workers. Workplace Health Saf. 2019 Feb;67(2):96. [PubMed | DOI]

4. Mehta RK, Srivastav G, Neupane N, Shah DK. Work place violence among health personnel in tertiary health care institution of Nepal, 2015. International Journal of Multidisciplinary Research and Development. 2015 April;2(4):450-53. [Full Text]

5. Rajbhandari R, Subedi S, Kaphle HP. Workplace Violence against Health Workers: A Cross-Sectional Study from
Baglung District, Nepal. International Journal of Health Sciences and Research (IJHSR). 2015;5(2):274-81. [Full Text]

6. Gates DM, Gillespie GL, Succop P. Violence against nurses and its impact on stress and productivity. Nurs Econ. 2011 Mar-Apr;29(2):59-66. [PubMed]

7. Shoghi M, Sanjari M, Shirazi F, Heidari S, Salemi S, Mirzabeigi G. Workplace violence and abuse against nurses in hospitals in Iran. Asian Nurs Res (Korean Soc Nurs Sci). 2008 Sep;2(3):184-93. [uㅏbMed | DOI]

8. Embree JL, White AH. Concept analysis: nurse-to-nurse lateral violence. Nurs Forum. 2010 Jul-Sep;45(3):166-73. [PubMed | DOI]

9. World Health Organization. WHO recommended interventions for improving maternal and newborn health: integrated management of pregnancy and childbirth. Geneva (Switzerland): World Health Organization; 2007. [Full Text] 
10. Pandey M, Bhandari TR, Dangal G. Workplace Violence and its Associated Factors among Nurses. J Nepal Health Res Counc. 2018 Jan 1;15(3):235-41. [PubMed]

11. Cooper CL, Swanson N. Workplace violence in the health sector. State of the art [Internet]. Geneva (Switzerland): HRH Global Resource Centre. 2002. Available from: https:/ / www.hrhresourcecenter.org/node/1120.html. [Full Text]
12. di Martino V. Relationship between work stress and workplace violence in the health sector [Internet]. Geneva: International Labour Organization. 2003. Available from: https://www.worktrauma.org/health/wv_management_ victims.pdf. [Full Text]

This work is licensed under a Creative Commons Attribution 4.0 International License. The images or other third party material in this article are included in the article's Creative Commons license, unless indicated otherwise in the credit line; if the material is not included under the Creative Commons license, users will need to obtain permission from the license holder to reproduce the material. To view a copy of this license, visit http://creativecommons.org/licenses/by/4.0/ 